\title{
The interface of Medicare coverage decision-making and emerging molecular-based laboratory testing
}

\author{
Mitchell I. Burken, $M D, M P P^{I}$, Kathleen S. Wilson, $M D, F A C M G^{2}$, Karen Heller, $M S^{2}$, \\ Victoria M. Pratt, PhD, FACMG ${ }^{3}$, Michele M. Schoonmaker, PhD ${ }^{4}$, and Eric Seifter, $M D^{5}$
}

\begin{abstract}
The process of obtaining Medicare coverage for clinical services (both at the national and local levels) can be complex and often leads to considerable confusion among external stakeholders. The entry of molecular diagnostic testing into the clinical arena of laboratory medicine has posed some special challenges, both for those providing the testing, and those paying for such technology. This commentary will seek to clarify Medicare's pursuit of defining medical necessity by describing both the local and national Medicare coverage policy processes. However, it should be understood that the Medicare reimbursement for such esoteric testing is a work-in-progress, without an established step-by-step process for obtaining a positive coverage decision. Yet, this evolving process provides all stakeholders (payers, laboratories, industry, clinicians, etc.) with an opportunity to fully understand the health policy implications of complex molecular diagnostic testing. In addition, brief case study vignettes are incorporated into our discussion, to show how laboratorians, in conjunction with their clinical colleagues, can effectively engage the payer community in developing more medically sound and fiscally responsible coverage policies. Genet Med 2009:11(4):225-231.
\end{abstract}

Key Words: genetic testing, laboratory testing, local coverage determination, national coverage, determination, medicare, test selection, test translation, clinical validity, clinical utility

$\mathrm{T}$ he emergence of new, and often complex, molecular diagnostic tests has placed new responsibilities on the payer community to properly evaluate the medical necessity of such esoteric testing. This commentary will offer constructive guidance for laboratorians and clinicians to more effectively navigate the Medicare coverage development process. Additionally, the discussion is intended to be sufficiently broad as to apply to many activities of the private payer community, in addition to Medicare. First, however, it is essential to identify barriers that are specific to the evaluation of molecular diagnostics.

From ${ }^{1}$ IntegriGuard, LLC, Columbia, Maryland; ${ }^{2}$ Department of Pathology, The University of Texas Southwestern Medical Center at Dallas, Dallas, Texas; ${ }^{3}$ Department of Molecular Genetics, Quest Diagnostics, Chantilly, Virginia; ${ }^{4}$ Cepheid, Washington DC; and ${ }^{5}$ The Johns Hopkins University School of Medicine and the Sidney Kimmel Comprehensive Cancer Center, Baltimore, Maryland.

Kathleen S. Wilson, MD, FACMG, Chief, Division of Genetic Diagnostics, Director, CGH Microarray Laboratory, Associate Professor, McDermott Center for Human Growth and Development, U.T. Southwestern Medical Center, 6000 Harry Hines Blvd., Hamon Building, Room NA2.508A, Dallas, Texas 753908591. E-mail: kathleen.wilson@ utsouthwestern.edu.

Disclosure: M.I.B. was formerly employed as a Medicare Part B contractor Medical Director with TrailBlazer Health Enterprises, LLC, and before that, as a Medical Officer with the Coverage \& Analysis Group at the Centers for Medicare \& Medicaid Services.

Submitted for publication June 19, 2008.

Accepted for publication December 2, 2008.

DOI: $10.1097 /$ GIM.0b013e3181976829

\section{The medicare coverage process: Providing a baseline for further discussion}

There is a relative dearth of formal molecular diagnostics requests for Medicare coverage, both at the national level, and at the local (state) level, but we will take the opportunity to illustrate some pertinent case study material. However, first, there is great value in presenting a comparative overview of the national and local Medicare coverage processes, such that the laboratory community can become more conversant with these potential options for obtaining reimbursement.

The payment by the Centers for Medicare \& Medicaid Services (CMS) for items and services furnished to Medicare beneficiaries is predicated upon the determination of medical reasonableness and necessity, according to Title XVIII of the Social Security Act, Section 1862 (a) (1) (A): “. . . No payment may be made under Part A or Part B for any expenses incurred for items or services which are not reasonable and necessary for the diagnosis or treatment of illness or injury or to improve the functioning of a malformed body member."1 Additionally, any item or service must be determined to fall within a benefit category. In other words, all items or services (e.g., durable medical equipment, physician service, diagnostic laboratory test) must adhere to the above statutory mandate, and there is a specific exclusion of preventive or screening services. Whereas separate statutory carve-out language has been necessary for Medicare coverage of screening services, recent passage of the Medicare Improvements for Patients and Providers Act of 2008 $(\mathrm{MIPPA})^{2}$ will lend greater flexibility to this process by more directly linking Medicare preventive services coverage evaluations to the national coverage determination $(\mathrm{NCD})$ process (see below). Finally, by force of law, Medicare generally does not use cost or cost-effectiveness as a criterion for "reasonable and necessary" determinations.

Although Medicare requires services to be "reasonable and necessary" for improving health outcomes, regulatory oversight standards for laboratory tests are largely less stringent. Laboratory tests may be marketed in two ways. Test kits made by manufacturers and sold to laboratories are regulated by the Food and Drug Administration (FDA). Novel or high-risk in vitro diagnostic tests are evaluated for "safety and effectiveness," through a stringent review process known as premarket approval. ${ }^{3}$ More established or lower risk tests are reviewed against a standard of "substantial equivalence" through the premarket notification $(510(\mathrm{k}))$ pathway. ${ }^{4}$ Alternatively, laboratories that develop their own genetic tests and market testing services are subject only to the usual requirements of the Clinical Laboratory Improvement Amendments (CLIA) which are administered by CMS and regulate all clinical laboratory operations. ${ }^{5}$ In contrast to FDA's review of individual tests, CLIA's oversight focuses on the quality of the laboratory testing process rather than a review of the attributes of the test itself. Although CLIA requires an assessment of the performance of the test by the 
laboratory, those data are not subject to an independent or in depth review.

In the respective CMS and FDA evaluations of in vitro laboratory testing, there may not exist a high degree of overlap between a test being deemed "reasonable and necessary" versus "safe and effective." Therefore, this variation between key regulatory bodies provides a major reason for laboratory testing stakeholders to become more fully conversant with both sets of mandates.

The formal policy pathways through which laboratory services may be granted coverage under the Medicare program include:(1) local coverage determinations (LCDs), formerly known as local medical review policies (LMRPs), and (2) NCDs. The role of either LCD or NCD is to create and publicly document the pairing of pertinent Current Procedural Terminology (CPT) codes to International Classification of Diseases, Version 9, Clinical Modification (ICD-9-CM) codes, describing what was done to a patient and why. ${ }^{6,7}$ This constitutes the basis for so-called "limited coverage" for both therapeutic and diagnostic services, where Medicare program vulnerabilities, such as potential overuse, may exist. Thus, the absence of a coverage policy denotes the fact that such special restrictions are not placed on a particular service. To illustrate this point, if a local contractor determined that no edit-based restrictions are necessary for a new laboratory assay, then there would be the specific omission of any policy constraints involving this new assay.

As summarized in Table 1, the NCD and LCD processes differ in some fundamental ways, ${ }^{8,9}$ yet there is still considerable concordance. Perhaps most fundamentally, an NCD decision is binding nationally, and overrules all LCDs regarding the same services. Where there is no overriding NCD for a service (i.e., where CMS is silent), individual LCDs may handle coverage/noncoverage of that service, and such LCDs need not be the same across local jurisdictions. Although complaints about the nonuniformity of the local coverage process are frequent, internal consistency is not a mandate. Furthermore, although there are respective appellate processes for both LCDs and NCDs, claims denials cannot be overturned by an administrative law judge for NCD-based claim adjudication, but such reversals are allowable under the governance of an LCD.

LCD requests for coverage that originate largely within the context of the Medicare contractor interactions with provider stakeholders, and are effective only within the local contractor's jurisdiction, whereas NCDs can be generated from a much broader base of requestors, including, but not restricted to, manufacturers, beneficiaries, providers, legislators, and even contractors themselves. Because local Medicare contractors tend to partner with local providers, often through local (and national) medical or laboratory science societies, requests originating from manufacturers are often expressed through local providers who have embraced emerging technologies (drugs, devices, etc.) within their practices, and who, in turn, contact contractors about coverage. In addition, both LCDs and NCDs can be internally generated, based upon policy needs, without the necessity for external requests.

Both NCDs and LCDs are predicated upon the public noticeand-comment process for the critique of draft material. As NCDs are being developed, there is a CMS website "Tracking Sheet" to annotate the various deliberative steps in the policy formulation. There exists a high premium on the systematic review of available peer-reviewed medical evidence, along with input from various stakeholders such as national specialty societies, industry, and consumer groups, with the "Decision Memorandum" serving as the major vehicle to express both the policy language, along with the rationale for such language. In contrast, LCDs have written LCD Records, which are available via the Freedom of Information Act (FOIA), and the accrual of LCD background information may be less systematic and/or comprehensive in nature, relying much more upon the local provider community for their involvement.

There is a mandated review of all proposed LCDs by Contractor Advisory Committees (CACs), which consist of discussing each individual LCD in draft form, and are convened 3-4 times per annum in each jurisdiction. Members of the CACs are appointed by state medical societies, with such membership being designed to reflect local clinical practice patterns. In contrast, at the national level, CMS may at its discretion choose to refer topics for contracted technology assessments via its agreement with the Agency for Health Research and Quality, and/or deliberations by the Medicare Evidence Development \& Coverage Advisory Committee (MedCAC), whose members are appointed by CMS.

Local contractors are more limited than CMS in their ability to perform evidence reviews and technology assessments, and local contractors tend to work with any available, published

Table 1 Comparative features of NCD and LCD processes

\begin{tabular}{ll}
\hline Descriptor & NCD \\
\hline Public notice-and-comment required & Yes \\
Key content drivers & $\begin{array}{c}\text { Systematic review of evidence, along } \\
\text { with national specialty society, }\end{array}$ \\
& industry, consumer, etc. input
\end{tabular}

Specifies procedure-to-diagnosis code pairings

Types of requests permissible

Use of external technology assessments

Advisory committee review

Ability to track ongoing deliberations on policy formulation

Binding nationally without appellate reversals by administrative law judges
Occasionally

Externally + internally-generated

Extensive

Optional MedCACs

Yes, can be done prospectively via CMS website "Tracking Sheet"
LCD

Yes

Evidence where available, in tandem with grassroots (local) provider input

Nearly always

Externally + internally-generated

As available

Mandatory CACs

Can only be done retrospectively by requesting written $\mathrm{LCD}$ Record via Freedom of Information Act (FOIA) 
technology assessments, or conduct their own literature reviews. They often depend upon requestors to send them the "best" supporting peer-reviewed literature. Whereas, the local CAC deliberations tend to reflect the more qualitative opinions of local organized medicine and individual providers, MedCACs are more characterized by quantitative, critical evaluations of the available evidence. There exist ample opportunities for molecular pathology experts to engage in both the national MedCAC and local CACs, per those membership guidelines already established by CMS. ${ }^{10,11}$

As previously mentioned, the LCD is a working business document designed to enable electronic edits to autoadjudicate claims via the assignment of limited diagnostic codes to specific procedure (CPT) codes. This differs somewhat from the policyoriented NCDs, where the specification of the actual code pairings is left to the local contractors, based upon the NCD language. Occasionally, in fact, local contractors will develop LCDs specifically to implement NCDs, but this is usually not necessary. Local contractors usually institute edits directly based upon the NCD. An exception to this nonprovision of code pairings by NCDs is the November 2001 CMS rule regarding laboratory $\mathrm{NCDs},{ }^{12}$ which, in fact, specifies code pairings for many commonly ordered (e.g., chemistry, hematology) laboratory tests.

Finally, there are some special features of the local coverage process, that do not directly involve notice-and-comment LCD development. The most common occurrence is when a local provider requests an expansion of coverage (i.e., a new codepairing), based upon what the provider perceives is an omission in the current LCD. In this situation, the provider can write the local Contractor Medical Director (CMD), and, with attached supporting literature, request that the LCD be updated. This process does not require a new LCD to be developed. Referrals through the local CAC-based notice-and-comment process is not required if an LCD is being revised to further expand coverage, in contradistinction to the proposed restriction of coverage where notice-and-comment becomes necessary.

\section{CASE STUDIES}

We suggest that advocates of a new technology should organize their case in a logical, coherent manner, and depend upon either CMS staff or local CMDs to help guide them through the necessary administrative steps. So far, Medicare coverage activity regarding molecular diagnostics has been minimal. However, three brief case vignettes have been enclosed as sidebars, to highlight some current issues, and to help correlate such issues with the above process details. Please note that the third vignette has been partially fictionalized for illustrative purposes, given that a key impetus for this commentary is to stress the importance of Medicare being able to clearly evaluate emerging tests for their medical necessity. In this case study, it was critically important to demonstrate that a particular test added diagnostic value to the conventional pathology report, enabling patients to be more optimally managed.

\section{Vignette \#1: PreGen-Plus ${ }^{\mathrm{TM}}$ NCD request (for colorectal cancer screening)}

A currently marketed stool DNA assay for colorectal cancer (CRC) screening represents the molecular diagnostic laboratory test which had the greatest relative progress-to-date through the CMS NCD development cycle. However, a more recent topic (e.g., genetic profiling for warfarin dosing) is under consideration for possible NCD development. ${ }^{13}$ A specific statutory carve-out (i.e., the Balanced Budget Act of 199714) has rendered CMS the authority to evaluate new CRC screening tests for coverage, along with the special stipulation that cost-effectiveness may be considered for such coverage evaluations of new CRC screening tests. Regarding the stool DNA screening test, which assays several mutations, there are some sentinel lessons to be learned about the NCD process from the Decision Memorandum, ${ }^{15}$ which includes a comprehensive discussion that is structured according to the following six topical areas:

1. External technology assessments: Summaries of reports from both the BlueCross BlueShield Association Technology Evaluation Center (BCBSA TEC ${ }^{16}$ and the Agency for Health care Research and Quality Technology Assessment Program); ${ }^{17}$

2. Internal technology assessments: Review by CMS staff of four selected publications in the current peer-reviewed literature;

3. MedCAC recommendations: However, none in this case, as an elective MedCAC was not convened;

4. Evidence-based guidelines: In this case, from the United States Preventive Services Task Force - USPSTF;

5. Professional society position statements: From the American Gastroenterological Association, the American Society for Gastrointestinal Endoscopy, and a joint guideline from the American Cancer Society, the US Multi-Society Task Force on Colorectal Cancer and the American College of Radiology; and,

6. Public comments: From 154 commenters.

However, a full appreciation of this extensive NCD process can only be gained by review of the entire Decision Memorandum, because it provides an excellent indication of what type of evidentiary base is deemed as important for national coverage. Furthermore, although this particular coverage determination has been suspended on account of a pending FDA administrative clearance, the authors feel that this vignette provides a useful portrait of the NCD process and demonstrates the accrual of information which CMS deems pertinent for establishing a "reasonable and necessary" threshold. In other words, the authors feel that it has considerable illustrative value, despite this unresolved final coverage outcome.

\section{Vignette \#2: Oncotype DX ${ }^{\circledR}$ for breast cancer recurrence analysis}

Oncotype $\mathrm{DX}^{\circledR}$ is a tumor profile test based on gene expression which exemplifies the importance of local Medicare decisions in California, a particularly technology-intensive state. Medicare Part B pays for claims based on the state where the reference laboratory performs the test, rather than in the state where the patient lives. Thus, the local contractor for Medicare Part B Medicare in California has had a pre-eminent role in coverage decisions for molecular diagnostics. The laboratory obtained Medicare coverage based on evidence reported by Paik et al., ${ }^{18}$ in concert with the medical director's analytical approach (which was published in a 2007 Medicare contractor Provider Education Bulletin ${ }^{19}$ ). Paik et al. ${ }^{18}$ demonstrated that the therapeutic management of tamoxifen-treated, node-negative breast cancer patients would be strongly influenced by the Oncotype $\mathrm{DX}^{\circledR}$ test output, the Recurrence Score ${ }^{\mathrm{TM}}$, derived from a 21-gene expression panel. This coverage decision represents a specific instance of the LCD process we described in general terms, through which a new local coverage decision resulted from both favorable published evidence and enthusiastic support from the provider community. 
This 2004 Paik study used a nonrandomized, nonprospective design to illustrate that the patented Recurrence Score ${ }^{\mathrm{TM}}$ could serve as a useful risk classifier. Fixed, paraffin embedded specimens from a large randomized controlled trial (the National Surgical Adjuvant Breast and Bowel Project [NSABP] B-14) reduced sources of bias, and raised the credibility of this retrospective cohort study as an alternative to the randomized controlled trial approach for the assessment of net health outcomes. The most salient finding was that a low Recurrence Score ${ }^{\mathrm{TM}}$ was associated with a very low $(6.8 \%$, with $95 \%$ confidence interval $=4.0-9.6 \%)$ rate of distant recurrence at 10 years, thus enabling safer decisions with regard to withholding (likely) unnecessary chemotherapy. The study was quickly and strongly embraced by the clinical community (e.g., California oncologists), and as a result, local coverage by the California Medicare Part B contractor occurred about 1 year after the initial publication.

Since the initial coverage decision by Medicare Part B, additional Oncotype DX ${ }^{\circledR}$ studies have been published (see the well-annotated 2008 technology assessment by the BCBSA $\mathrm{TEC}^{20}$ ). Additional cohorts have corroborated the 2004 Paik findings, and provided data that the Oncotype $\mathrm{DX}^{\circledR}$ test is a more powerful risk classifier than conventional clinical decision aids such as Adjuvant! Online. Please note that some of these studies were either in press or in abstract form at the time of the initial California coverage decision.

\section{Vignette \#3: "Confusion" arising from a genetics testing LCD}

In some cases, coverage issues can arise as a result of feedback to the local contractor regarding denied claims. Although some of the facts of this vignette have been fictionalized for illustrative purposes, both the intent and applicability of this case study are highly relevant. In particular, the difficulties of applying limited coverage to molecular genetics/oncology CPT codes are considerable, because these codes are based on the procedural steps of a laboratory test and not the analyte, nor the medical application.

In this illustration, if a particular LCD (i.e., not withstanding the 2-digit CPT code modifiers, for molecular diagnostic testing, which are not currently adopted for Medicare claims processing) should restrict such procedure codes to individuals with a diagnosis of breast or colon cancer (at risk for hereditary breast or hereditary CRC), here is what could happen if a chronic lymphocytic leukemia patient received the following work-up, as recommended in the literature ${ }^{21-30}$ : First, in the cytogenetics laboratory, four fluorescence in situ hybridization (FISH) probes were used to detect the following chromosomal markers: (1) Deletion in the 13q14 band region; (2) Trisomy of chromosome 12; (3) Deletion in the 11q22 band region; and (4) Deletion of the TP53 (Tumor Protein p53) gene in the short arm of chromosome 17 . In addition, the flow cytometry laboratory tested ZAP-70 overexpression, and finally, the molecular pathology laboratory performed immunoglobulin heavy chain gene $\mathrm{IgV}_{\mathrm{H}}$ rearrangement analysis.

Without any LCD limits on coverage for FISH or flow cytometry, the FISH and ZAP-70 testing would get reimbursed, but the $\operatorname{IgV}_{\mathrm{H}}$ gene rearrangement analysis would get denied if the LCD restricted the coverage of molecular CPT codes (i.e., $83890-83914)$ to ICD-9 codes pertaining to breast or colon cancer, but not including the ICD-9 code for chronic lymphocytic leukemia. Thus, this particular claims denial has precipitated the need for that LCD to be carefully re-examined, with coverage expansions likely required for "reasonable and necessary" indications in addition to breast/colon cancer. Furthermore, this vignette highlights the key issue that, at the local contractor level, both the awareness and acknowledgment of coverage limits can often be the result of reactive inquiries to denied claims, rather than proactive requests for such expanded services.

To help facilitate a correlation between the vignettes, and the earlier discussions involving NCD/LCD process and evidence accrual, please refer to Table 2 for an annotation of these key points. Although incomplete in its full roll-out of the NCD process, Vignette \#1 demonstrates the interplay of various deliberative forces, and should assist future NCD requestors in their preparation. Vignette \#2 also pertains to the medically necessary use of multianalyte tests to provide a single result interpretation, and how at least one local Medicare contractor has acquired the sophistication to fully appreciate this nuance. Finally, Vignette \#3 teaches us that the need for policy refinement is ongoing, with the ability of the various stakeholders to successfully communicate with each other being an essential ingredient for improved policy development.

\section{DISCUSSION}

\section{Key issues pertaining to the consistency of molecular diagnostics coverage evaluations}

\section{There is a considerable lack of experience and familiarity with such complex testing, within the broad realm of coverage policy development}

The knowledge gap between CMS staff including CMDs, and their laboratory counterparts in the community, has contributed much to the present uncertainty about Medicare coverage for molecular diagnostics. This knowledge gap is bidirectional in nature. The generalist payer community staff, dealing with the full range of clinical services, often finds the technical complexity of such laboratory testing to be daunting. This may result in payers having a more natural inclination to direct their activities to "win-win" projects versus spending time on esoteric laboratory services that have relatively lesser penetrance into clinical practice. Conversely, the laboratory community may see Medicare coverage as an unstructured, opaque obstacle to the reimbursement of important, emerging laboratory tools. In fact, Medicare coverage, both nationally and locally, is designed to be an evolutionary, participatory undertaking where multiple stakeholders have great opportunities to help shape both local and national coverage.

\section{The biostatistical approaches, which will tend to define the coverage roadmap for multianalyte diagnostic tests, are not yet widely understood nor embraced by multiple stakeholders}

One further impediment to a more consistent, dialogue between payers and the laboratory community is the lack of a common currency on the biostatistical underpinnings of multiplex testing. The calculations of sensitivity, specificity, and predictive values from a standard $2 \times 2$ table has often sufficed as a consensus set of metrics for single analyte testing, and has a reasonably well-established foothold within the realm of general medical knowledge. However, the emerging use of multiplex-driven biomathematics is required to handle specialized analytical hazards such as "overfitting" (i.e., the potentially inappropriate inclusion of individual biomarkers, within the constructed panel, which may have presumed statistical relevance in the absence of legitimate biological plausibility). These approaches are not currently part of the established mainstream medical and scientific lexicon for evaluating diagnostic studies, 
Table 2 Correlating vignettes with NCD/LCD process and evidence highlights

\begin{tabular}{lc}
\hline Vignette & Process correlation \\
\hline$\# 1:$ PreGen-Plus ${ }^{\mathrm{TM}}$ NCD request & $\begin{array}{c}\text { Relatively complete illustration of NCD information } \\
\text { gathering process, relative to other nascent NCD } \\
\text { efforts (e.g., Warfarin dosing). }\end{array}$
\end{tabular}

Even the deferral to a future NCD consideration, pending FDA decision-making, should not detract from readers appreciating the breadth of NCD information accrual.

\section{\#2: Oncotype $\mathrm{DX} \circledast \mathrm{LCD}$ request}

Represents first medicare local contractor to favorably rule upon a complex molecular assay.

Highlights the overall importance of provider community support in the determination of local coverage for emerging technologies.

\#3: "Confusion" from a genetics testing LCD
This is the most subtle, abstract vignette, which uses a more speculative approach for illustrative purposes only.

Demonstrates how one particular LCD may restrict the use of emerging molecular testing (e.g., $\operatorname{IgV}_{\mathrm{H}}$ mutational analysis for CLL treatment) because the requisite inclusiveness of ICD-9/CPT pairings is not present.
Evidence correlation

The structured Decision Memorandum, with its presentation of the evidence, in tandem with stakeholder commentary, is a highlyrepresentative snapshot of the NCD process.

This evidence should be viewed as complementary, and not deferential, to whatever companion FDA decisions might occur.

Note relatively high-quality evidence with strong clinical validation using outcomesbased data.

Showcases an important "tension" between the evidentiary bars for the NCD vs. the LCD.

Demonstrates how less powerful "prognostic" studies, which many local oncologists already use to guide their CLL therapy, may be acceptable in the LCD setting, although not necessarily acceptable in the NCD setting where more robust, treatment-based "predictive" studies are warranted. and as a result, some reasonable rate of educational diffusion of this biomathematics needs to be expected (e.g., as part of future medical school, clinical sciences, and health policy curricula).

Furthermore, it remains hopeful this biomathematics will help to resolve continuing evidentiary dilemmas, and that key principles can come into greater focus by the payer community. To illustrate, it is first essential for payers to understand the difference between diagnostic test clinical validity studies (i.e., those establishing the strength of association between biomarkers and outcomes of interest, using epidemiological data profiling) and clinical utility studies (either via randomized clinical trials [RCTs] or sufficiently robust, nonrandomized comparative cohort designs), which demonstrate if/how using the test results to change management decisions improves patient outcomes versus not using the test. Second, payers must then appreciate the need to factor both clinical validity and clinical utility studies into their coverage evaluations.

\section{Task force initiatives serve a highly useful function in the formulation of leading-edge ideas, but, to date, they have had limited adoption of their recommendations among the mainstream community of laboratorians, clinicians, and payers}

The recent proliferation of diverse task-force activities in the genetic testing arena, when viewed in the context of this aforementioned discussion, may create considerable opportunities for innovation and progress by the payer community. As genetic and molecular testing cuts an extremely broad swath through social, ethical, clinical, and scientific issues, it is probably a fair demarcation to briefly mention those initiatives which are more policy-based, versus those which are more evidence-based. In the former category, the broad policy overviews such as the Secretary's Advisory Committee on Genetics, Health, and So- ciety (SACGHS) serve as a public forum for defining issues raised by the development and use of genetic tests and, as warranted, to provide advice on these issues. ${ }^{31}$ Similarly, the Presidents Counsel of Advisors on Science and Technology (PCAST) recently issued a report discussing policy issues relevant to technologies and tools, regulation and reimbursement of medical products, including tests, in the emerging medical discipline of personalized medicine. ${ }^{32}$ Hopefully, payers will include such background global perspectives in their coverage deliberations.

Regarding the latter category, where more evidence-driven, drill-downs need to occur, comprehensive reviews of clinical validity and clinical utility by various national and international groups are very useful for the payer community. One example is the Agency for Health care Research and Quality, ${ }^{33}$ which has provided an informative review of multiple scales for the ranking of medical evidentiary strength, including all types of study designs. A second example is a systematic review of gene expression profiling for breast cancer where the (aforementioned) BCBSA TECreport ${ }^{20}$ has outlined a pertinent validation sequence, which can apply to a full complement of molecular testing. Similarly, other examples include the $\mathrm{ACCE}^{34}$ initiative (Analytical validity, Clinical validity, Clinical utility, and Ethical, legal, and social implications), via support from the Centers for Disease Control \& Prevention (CDC), and The American College of Medical Genetics ${ }^{35}$ has also provided invaluable syntheses of genomic testing. In addition, the CDC-funded EGAPP (Evaluation of Genomic Applications in Practice and Prevention) Working Group ${ }^{36}$ has enabled an independent, nonfederal, multidisciplinary panel of experts to convene on the state of the evidence of genetic testing. Most recently, another independent organization, the Center for Medical Technology Policy (CMTP) $)^{37}$ is developing guidance documents for rele- 
vant evidence accrual, regarding salient clinical problems such as early-stage breast cancer gene expression profiling (e.g., suggesting either randomized or nonrandomized comparative cohort designs for predictive studies versus less-stringent, nonrandomized single cohort designs for prognostic studies).

All of these public and private efforts overlap somewhat in scope, intent and even recommendations, yet the efforts are not necessarily related or coordinated in a meaningful way, thus making it difficult for nongeneticist medical directors to maintain an awareness of current thinking. However, CMD awareness of such ongoing policy initiatives may facilitate better coverage decisions.

\section{Because regulatory requirements are focused on analytic validity, evidence-based analysis has been slow to gain traction in clinical laboratory medicine. In addition, the finances of the diagnostics industry, unlike the pharmaceutical industry, are not as well- structured for studies of clinical validity and utility}

The statutory authorities of CMS (both for coverage and marketing of laboratory developed tests under CLIA) and FDA establish different levels of evidence required to meet thresholds for "approval" by the respective agencies. CMS' standard of "reasonable and necessary" generally requires health outcomes data (e.g., cure, disease-free survival, etc), preferably from RCTs, to determine the impact of the test on patient management. FDA, on the other hand, is allowed by law to consider surrogate outcomes (e.g., lower blood pressure, lower analyte level, etc.) in meeting the standard of "safe and effective." RCTs are rarely performed for any in vitro diagnostic devices, and to demonstrate "substantial equivalence," a test developer need only to show that the new test performs similarly to a test already cleared (i.e., predicate device) or that was on the market before 1976 (i.e., introduction of the Medical Device Amendments).

CLIA does not require any particular threshold of evidence, but only that the laboratory validate the test internally. CLIA regulations are designed to assure the quality of laboratory testing. The FDA assesses the clinical validity of genetic tests insofar as it is charged with assessing "safety and effectiveness." Its evaluation of clinical performance during reviews of premarket approvals, de novo $510(\mathrm{k})$, and $510(\mathrm{k})$ depends on the nature of the test, its intended use, and the amount of existing information about the associations of genetic markers and clinical diagnosis. ${ }^{38}$ Because most genetic tests are either laboratory developed (and thus regulated under CLIA) or cleared through the $510(\mathrm{k})$ process, clinical outcomes data that will be required for the coverage determination are often not collected during the validation phase.

This gap in evidentiary standards (between FDA and CMS) results in tests being on the market, available to patients, and yet without potential reimbursement. Requiring test developers to collect data to meet CMS standards tends to be administratively and economically burdensome, particularly if such test developers have not been aware of the above local versus national pathways for seeking Medicare coverage. Consequently, this evidentiary gap must be crossed for patients to have access to beneficial genetic tests.

The aforementioned evidence accrual initiatives, particularly CMTP guidance documents, ${ }^{37}$ will ideally help to assist with dual FDA and payer navigation. Through public policy forums, some mentioned earlier, and others supported by each individual agency, FDA and CMS have been exploring ways to collaborate with test developers for the collection of better clinical data in a postmarket setting, because FDA can also require postmarket studies as a condition of approval.

The existing (CPT-based) procedure coding structure (particularly among genetic tests) is too ill-defined and not test-specific. Furthermore, it tends to be relatively incomprehensible other than to those highly-trained in performing the tests

Finally, CPT coding, particularly regarding noninfectious molecular pathology assays, is highly confusing to the payer community. The CPT codes for testing in genetics and molecular oncology are based on steps of the assay. Laboratories may perform tests for a given gene or condition using different methods. Although each method may have the exact same result, the CPT codes used to report the test to a payer will be completely different. Recently, modifier codes were added to the molecular CPT $\operatorname{codes}^{6}$ to help payers identify some of the disorders being tested. However, at this point, very few payers (including Medicare) are able to use these modifiers in their claims processing systems, further noting that they are incomplete and lag behind the introduction of new tests.

The lack of condition-, gene-, or disease-specific codes is an obstacle when defining a coverage policy because payers are not able to identify the type of result generated by the test or the clinical reason for its request. In other words, a procedural step (e.g., amplification) may be used in many different tests for many different diseases, with Vignette \#3 illustrating this dilemma. Without the modifiers or other specific information, payers are unable to determine if the "medically reasonable or appropriate" gene or genetic target is being tested given a patient's clinical condition. There are multiple ongoing policy efforts in this area, which are beyond the scope of this coverage-related commentary.

\section{CONCLUSION}

Hopefully, it has become clear that advocacy for Medicare coverage, in the area of advanced laboratory diagnostics, can be much more effective if it is systematically orchestrated by the pertinent laboratory and clinician stakeholders. We have illustrated a few vignettes, which reflect some early Medicare coverage policy experiences to date, but also reinforce that highly focused efforts are necessary to override some existing uncertainties and potential barriers. By creating more transparent, prescriptive avenues at both the national and local levels we can forge more constructive relationships between the payer community and molecular pathology stakeholders, thus supporting the critical role of diagnostic patient care.

\section{ACKNOWLEDGMENTS}

The authors thank Dr. Bruce Quinn, former California Medicare Medical Director (National Heritage Insurance Corporation) regarding his contribution, particularly with respect to Vignette \#2, and Kendall Walker, Esq., BlueCross BlueShield of South Carolina for his invaluable legal assistance, in supporting the legal/regulatory efforts of this article.

\section{REFERENCES}

1. 42 U.S.C. \$1395y(a) (1)(A) (2000); see also Centers for Medicare \& Medicaid Services, U.S. Department of Health and Human Servs., Pub. No. 100-2, Medicare Benefit Policy Manual, ch. 16, § 20, Available at: http:// www.cms.hhs.gov/manuals/downloads/bp102c16.pdf. Accessed August 7, 2008 .

2. Available at: http://frwebgate.access.gpo.gov/cgi-bin/getdoc.cgi? dbname $=110$ cong bills\&docid=f:h6331enr.txt.pdf. Accessed November 24, 2008. 
3. 21 C.F.R. $\$ 814.2$. Available at: http://www.accessdata.fda.gov/scripts/cdrh/ cfdocs/cfCFR/CFRSearch.cfm?fr=814.2. Accessed September 24, 2008.

4. 21 C.F.R. Part 807. Available at: http://www.accessdata.fda.gov/scripts/ $\mathrm{cdrh} / \mathrm{cfdocs} / \mathrm{cfcfr} /$ CFRSearch.cfm?CFRPart $=807$. Accessed September 29 , 2008.

5. 42 C.F.R Part 493. Available at: http://www.cdc.gov/clia/regs/toc.aspx. Accessed September 29, 2008.

6. American Medical Association. Current procedural terminology. American Medical Association, 2009.

7. Practice Management Information Corporation. International classification of diseases, 9th Revision, Clinical modification, 6th ed. Practice Management Information Corporation, 2009.

8. Medicare program: Revised process for making medicare national coverage [DONE] determinations, 68 Fed. Reg. 55,634 (September 26, 2003). Available at: http://www.cms.hhs.gov/DeterminationProcess/Downloads/ FR09262003.pdf. Accessed August 7, 2008.

9. Centers for Medicare \& Medicaid Services, U.S. Department of Health and Human Servs. Pub. No. 100-8, Medicare Program Integrity Manual, ch. 13. Available at: http://www.cms.hhs.gov/manuals/downloads/pim83c13.pdf. Accessed August 7, 2008.

10. Medicare program; Renewal and Renaming of the Medicare Coverage Advisory Committee (MCAC) to Medicare Evidence Development Coverage Advisory Committee (MedCAC) and a Request for Nominations for Members for the Medicare Evidence Development \& Coverage Advisory Committee, 72 Fed. Reg. 3,853 (January 26, 2007). Available at: http:// www.cms.hhs.gov/faca/downloads/renew07.pdf. Accessed August 7, 2008.

11. Centers for Medicare \& Medicaid Services, U.S. Department of Health and Human Servs. Pub. No. 100-8, Medicare Program Integrity Manual, ch. 13. Available at: http://www.cms.hhs.gov/manuals/downloads/pim83exhibits.pdf. Accessed August 7, 2008

12. Centers for Medicare \& Medicaid Services, U.S. Department of Health and Human Servs., Pub. No. 100-4, Medicare Claims Processing Manual, ch. 16, §120. Available at:http://www.cms.hhs.gov/manuals/downloads/ clm104c16.pdf. Accessed August 7, 2008.

13. Available at: http://www.cms.hhs.gov/mcd/viewtrackingsheet.asp?id=224. Accessed August 7, 2008.

14. Balanced Budget Act of 1997, Public Law No. 105-33, § 4194; 1997.

15. Available at: http://www.cms.hhs.gov/mcd/viewdecisionmemo.asp?id=212. Accessed August 7, 2008.

16. Fecal DNA special report: Analysis for colon cancer screening. BlueCross BlueShield Association Technology Evaluation Center Assessment Program 2006; 21. Available at: http://www.bcbs.com/blueresources/tec/vols/21/ 21 06.pdf. Accessed August 7, 2008.

17. Zauber AG, Lansdorp-Vogelaar I, Wilschut J, Knudsen AB, van Ballegooijen M, Kuntz KM. Cost-effectiveness of DNA stool testing to screen for colorectal cancer. AHRQ Technology Assessment Program 2007, Available at: http://www.cms.hhs.gov/mcd/viewtechassess.asp?id=212. Accessed August 7, 2008.

18. Paik S, Shak S, Tang G, et al. A multigene assay to predict recurrence of tamoxifen-treated, node-negative breast cancer. N Engl J Med 2004;351: 2817-2826.

19. NHIC. Approaches to coverage determinations for complex molecular testing. Provider Education Bulletin, Medicare Part B, California, NHIC, Corp., 2007.
20. Gene expression profiling of breast cancer to select women for adjuvant chemotherapy. BlueCross BlueShield Association Technology Evaluation Center Assessment Program 2008;22. Available at: http:/www.bcbs.com/ blueresources/tec/vols/22/22 13.pdf. Accessed August 7, 2008.

21. Shanafelt TD, Witzig TE, Fink SR, et al. Prospective evaluation of clonal evolution during long-term follow-up of patients with untreated early-stage chronic lymphocytic leukemia. J Clin Oncol 2006;24:4634-4641.

22. Orchard JA, Ibbotson RE, Davis Z, et al. ZAP-70 expression and prognosis in chronic lymphocytic leukemia. Lancet 2004;363:105-111.

23. Dohner H, Stilgenbauer S, Benner A, et al. Genomic aberrations and survival in chronic lymphocytic leukemia. N Engl J Med 2000;343:1910-1916.

24. Athanasiadou A, Stamatopoulos K, Tsompanakou A, et al. Clinical, immunophenotypic, and molecular profiling of trisomy 12 in chronic lymphocytic leukemia and comparison with other karyotypic subgroups defined by cytogenetic analysis. Cancer Genet Cytogenet 2006;168:109-119.

25. Byrd JC, Gribben JG, Peterson BL, et al. Select high-risk genetic features predict earlier progression following chemoimmunotherapy with fludarabine and rituximab in chronic lymphocytic leukemia: justification for riskadapted therapy. J Clin Oncol 2006;24:437-443.

26. Dewald GW, Brockman SR, Paternoster SF, et al. Chromosome anomalies detected by interphase fluorescence in situ hybridization: correlation with significant biological features of B-cell chronic lymphocytic leukaemia. $\mathrm{Br} J$ Haematol 2003;121:287-295.

27. Hamblin TJ, Davis Z, Gardiner A, Oscier DG, Stevenson FK. Unmutated Ig $\mathrm{V}_{\mathrm{H}}$ genes are associated with a more aggressive form of chronic lymphocytic leukemia. Blood 1999;94:1848-1854

28. Grever MR, Lucas DM, Dewald GW, et al. Comprehensive assessment of genetic and molecular features predicting outcome in patients with chronic lymphocytic leukemia: results from the US intergroup phase III trial E2997. J Clin Oncol 2007;25:799-804.

29. Stilgenbauer S, Dohner H. Campath-1H-induced complete remission of chronic lymphocytic leukemia despite $p 53$ gene mutation and resistance to chemotherapy (letter to the editor). N Engl J Med 2002;347:452-453.

30. Lozanski G, Heerema NA, Flinn IW, et al. Alemtuzumab is an effective therapy for chronic lymphocytic leukemia with p53 mutations and deletions. Blood 2004;103:3278-3281.

31. Available at: http://www4.od.nih.gov/oba/SACGHS/reports/SACGHS_PGx_ Report.pdf. Accessed September 26, 2008.

32. Available at: http://www.ostp.gov/galleries/PCAST/pcast_report_v2.pdf. Accessed September 26, 2008.

33. Systems to rate the strength of scientific evidence: evidence report/technology assessment number 47. Prepared for: Agency for Healthcare Research and Quality, 2002. Available at: http://www.ncbi.nlm.nih.gov/books/ bv.fcgi?rid=hstat1.chapter.70996. Accessed August 7, 2008.

34. Haddow JE, Palomaki GE. ACCE: a model process for evaluating data on emerging genetic tests, 2003. Available at: http://www.cdc.gov/genomics/ gtesting/ACCE.htm.1. Accessed August 7, 2008

35. Available at: http://www.acmg.net. Accessed September 29, 2008.

36. Available at: http://www.egappreviews.org. Accessed August 7, 2008.

37. Available at: http://www.cmtpnet.org/tech-policy-working-group. Accessed August 7, 2008

38. Available at: http://oba.od.nih.gov/oba/SACGHS/reports/SACGHS_oversight_ report.pdf. Accessed November 20, 2008. 